\title{
The feasibility of an experimental model of donors after cardiac death in remote ischemic preconditioning studies for renal transplantation in porcine ${ }^{1}$
}

\author{
João Paulo Figueiredo Camarço ${ }^{\mathrm{I}}$, Lucio Kenny Morais ${ }^{\mathrm{II}}$, Juan Duque Moreno ${ }^{\mathrm{III}}$, Matheus Castrillon Rassi' ${ }^{\mathrm{IV}}$, Mylena Naves de \\ Castro Rocha Camarçov, Pedro Figueiredo Guimarães ${ }^{\mathrm{VI}}$, Claudemiro Quireze Júnior ${ }^{\mathrm{VII}}$ \\ ${ }^{I}$ Fellow Master degree, Postgraduate Program in Health Sciences, Federal University of Goias (UFG), Goiania-GO, Brazil. Intellectual and scientific \\ contents of the study, technical procedures, manuscript writing. \\ II Fellow Master degree, Postgraduate Program in Health Sciences, UFG, Goiania-GO, Brazil. Acquisition and interpretation of data, manuscript writing.

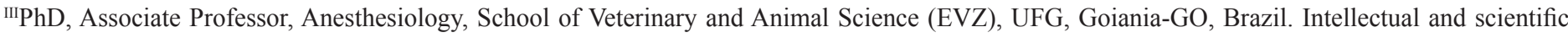 \\ content of the study, technical procedures, manuscript writing.

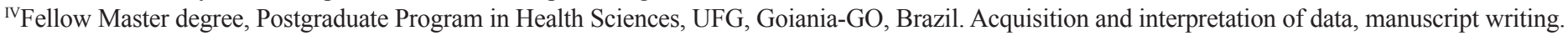 \\ vAssistant Professor, Department of Obstetrics/Gynecology, Pontifical Catholic University of Goias (UCG), Goiania-GO, Brazil. Critical revision, \\ ${ }^{\mathrm{VI}}$ Graduate student, Departament of Surgery, Catholic University of Brasilia (UCB), Brasilia-DF. Acquisition of data, technical procedures. \\ ${ }^{\mathrm{VII}} \mathrm{PhD}$, Associate Professor, Surgical Clinics, UFG, Goiania-GO, Brazil. Intellectual and scientific contents of the study, technical procedures, \\ manuscript writing.
}

\begin{abstract}
PURPOSE: To evaluate the feasibility of an experimental model of donors after cardiac death in remote ischemic preconditioning studies. METHODS: Twelve Landrace pigs were used as organ donors. They underwent cardiac arrest by coronary en block suture and interruption of ventilatory support. Haemodynamic data regarding the donor surgical protocol were evaluated. Studies variables included mean heart rate, systolic blood pressure, diastolic blood pressure, mean arterial pressure, central venous pressure and oxygen saturation and the time to death.

RESULTS: Haemodynamic parameter indicated that the circulatory failure occurred after nine minutes of en block coronary suture and respiratory support interruption. The circulatory collapse occurred evenly across all groups. The heart rate and central venous pressure were statistically different between groups $(\mathrm{p}=0.023$ and $\mathrm{p}=0.04)$, respectively. The remote preconditioning resulted in delayed time of death.
\end{abstract}

CONCLUSIONS: The model is feasible, and was easily reproduced. The ischemic remote preconditioning tends to a slight increase in circulatory failure time.

Key words: Ischemic Preconditioning. Kidney Transplantation. Organ Preservation. Swine. 


\section{Introduction}

Ischemic preconditioning, a phenomenon induced by brief ischemia and reperfusion periods, renders an organ more tolerant to subsequent sustained ischemia-reperfusion injury ${ }^{1}$

This phenomenon has been studied and characterized mainly in the heart, but it has also been described in the liver, small intestine, and brain, however, little information is available for the kidney ${ }^{1,2}$

Therefore, novel therapeutic modalities to prevent renal injury from ischemia are urgently needed, and studies on molecular mechanisms of renal ischemic injury have been areas of intense investigation. A very promising experimental strategy to improve ischemic tolerance of the kidneys is the remote ischemic preconditioning (IRPc) $)^{3}$.

In fact, pre-treatment with short periods of ischemia dramatically increases renal resistance to a second ischemic injury. Even though multiple attempts have been undertaken to identify molecular mechanisms that are involved in renal protection by Ischemic preconditioning, the underlying molecular mechanisms are largely unknown ${ }^{4}$.

Donors after cardiac death (DCD) have been reintroduced into clinical practice because of the progressively rising number of patients on the transplant waiting list and relatively static numbers of cadaveric organ donors. Several medical centers have undertaken DCD programs utilizing category 4 of Maastricht criteria. The current data show encouraging outcomes, which give rise to further interest in this donor pool ${ }^{5}$.

One way to increase the number of organs available for transplant is the improvement of grafts from DCD, as an alternative source to increase organ supply ${ }^{5-8}$.

Despite the high rate of early graft dysfunction of organs from DCD compared with living donors, DCD, have better quality of life and survival compared to patients in dialyis ${ }^{5,9,10}$.

The study of these organs requires a uniform model for the purpose of scientific comparisons. In almost no country are there professional guidelines or legal definitions to determine when death can be certified and when the process is sufficiently established to permit organ retrieval ${ }^{8}$.

Organs from DCD may mimic a marginal organ in a controlled manner. Although there are several experimental methods to simulate a donor in cardiac arrest there is yet no standardization established ${ }^{11,12}$.

Morais et al. ${ }^{13}$ designed a new experimental model of DCD. Validated for studies on the liver transplant model, it is useful for its simplicity and effectiveness in promoting cardiac arrest. Despite the encouraging reproducibility of this model, little is known in regard to the influence of IRPc on the donor before cardiac death. Therefore, this paper focuses on effects of IRPc on the DCD.

The aim of this study is to evaluate the applicability of the new experimental model proposed by Morais et al. ${ }^{13}$, evaluating ischemic remote preconditioning treatment in the context of renal transplantation.

\section{Methods}

This project was revised and approved by the Ethics in Research of the Hospital of the Faculty of Medicine, Federal University of Goias, under registration 00139/2011.

The experimental animal model in cardiac arrest was performed at the Laboratory for Research in Experimental Surgery of the School of Veterinary Medicine, UFG, in the period of January-February 2012.

We followed the principles of international research on animals in accordance with the Federal Law 11,794 of October 8, 2008, decree number 6689 of 15 July 2009 regulating the use of experimental animal in Brazil, being the surgeries supervised by veterinary anesthetist

We used 15 male Landrace pigs, weighing between 24$31 \mathrm{~kg}$ (average of $27.375 \mathrm{~kg}$ ). The animals were used as organ donors according to NHBD protocol designed by Morais et al. ${ }^{13}$ There were 3 deaths during the anaesthetic procedures.

\section{Experimental design or protocol}

Group 1 - Control group (en block suture ligation of coronary arteries followed by respiratory disconnection).

Group 2 - Subjected to ischemic remote preconditioning.

Group 3 - Subjected to ischemic remote preconditioning plus 15 minutes of normothermic ischemia.

Group 4 - Subjected to ischemic remote preconditioning plus 30 minutes of normothermic ischemia.

CHART 1 - Experimental design or protocol.

\begin{tabular}{ccccc}
\hline Groups & I & II & III & IV \\
\hline Donors & NHBD & NHBD & NHBD & NHBD \\
RPc & NO & YES & YES & YES \\
NI & 0 & 0 & $15 \mathrm{~min}$ & $30 \mathrm{~min}$ \\
\hline
\end{tabular}

NHBD: Non-Heart-Beating Donor. IRPc: Ischemic Remote Preconditioning. NI: Normothermic Ischemia 
The utilization of groups 3 and 4 with increased duration of normothermic ischemia aims at the evaluation of the graft response in the recipient, as a continuation of the same study. In fact, these groups are similar to group 2 and were used to increase the sample size, since they don't cause interference in circulatory patterns of the donor.

\section{Anesthetic protocol and hemodynamic monitoring}

The animals were provided by the School of Agronomy and Veterinary of UFG and accommodated for a period of ten days under observation and maintenance. They were kept under standard laboratory conditions and fasted for 12 hours prior to surgery in the vivarium of the School of Veterinary Medicine, UFG, and received pre-medication with azaperone (2 mg.kg-1). After ten minutes ketamine (10 mg.kg-1), midazolam (0.5 mg.kg-1) and meperidine (4 mg.kg-1) were administered intramuscularly. The marginal ear vein was cannulated and anesthesia was induced with propofol (5-10 mg.kg-1) intravenously. Lines were placed at the internal carotid artery and both jugular veins for pressure measurements and fluid infusion.

General anesthesia was maintained with isoflurane and continuous infusion of fentanyl (10 microg.kg-1) and atracurium (0.4 mg.kg-1 / hour). The normocapnia was achieved by positive pressure ventilation among $35-45 \mathrm{mmHg}$.

The monitoring was performed with cardioscope $\left(\right.$ Dixtal $\left.^{\circledR}\right)$, oximetry, mean arterial pressure in the internal carotid artery cannulation and central venous pressure in the internal jugular vein cannulation with placement in the right atrium.

Donors variables were recorded in the first minute after en block suture of the coronary arteries and repeatedly after every two minutes, until the absence of central arterial pulse was reached and either isoelectric line or ventricular fibrillation to cardioscope (T1-time after 1 min. myocardial infarction; T3 - time after 3 min. myocardial infarction; T5 - time after 5 min. myocardial infarction; T7 - time after 7 min. myocardial infarction; T9 - time after 9 min. myocardial infarction).

After cardiac arrest, the kidney was procured and further exsanguination completed the euthanasia.

\section{Operative procedures}

The animals underwent thoraco-abdominal laparotomy, dissection of the abdominal aorta above the bifurcation of the Iliac Arteries and proceeded with the remote ischemic preconditioning defined as aortic clamping for ten minutes and releasing for ten minutes.
Once checked the time of each group, heparinization was performed $(500 \mathrm{UI} / \mathrm{kg})$, following suture of the coronary arteries and ventilatory support disconnection.

Donors variables studied were the mean values of: heart rate, systolic blood pressure, diastolic blood pressure, mean arterial pressure, central venous pressure, oxygen saturation and time to death.

\section{Statistical analysis}

Data entered on Excel database and subsequent analysis in SPSS 17.0 software.

For the analysis of time to death of the donor, the results were presented as mean and standard deviation. As all variables were normally distributed in all groups (KS: $>>0.05$ ), we applied the Student $t$ test.

For the analysis of cardiovascular parameters (heart rate, mean arterial pressure, oxygen saturation and central venous pressure), the results were presented as mean and standard deviation. As all variables were normally distributed in all groups (KS: $\mathrm{p}>0.05$ ). The test was analysis of variance.

For all tests the $95 \%$ level of confidence was set up, considering significant $\mathrm{p}<0.05$.

\section{Results}

The groups of animals subjected to the effect of ischemic or emote preconditioning delayed death time averaged one minute. But only between groups 1 and 2 statistical significance was observed $(\mathrm{p}=0.015)$.

TABLE 1 - Mean time to death in the donor animals.

\begin{tabular}{ccc}
\hline Group & $\begin{array}{c}\text { Mean time to death } \\
\text { in min. }\end{array}$ & Standard Deviation \\
\hline Group 1 & 9 min. & +-0.6 \\
Group 2 & 10 min. & +-0.2 \\
Group 3 & 10 min. & +-4.2 \\
Group 4 & 10 min. & +-1.7 \\
\hline
\end{tabular}

TABLE 2 - Comparison between the average for the time of death of the donor groups.

\begin{tabular}{cccc}
\hline Groups & & Groups & $\mathbf{p}$ \\
\hline Group 1 & $\mathrm{X}$ & Group 2 & $\mathrm{p}=0.015$ \\
Group 1 & $\mathrm{X}$ & Group 3 & $\mathrm{p}=0.175$ \\
Group 1 & $\mathrm{X}$ & Group 4 & $\mathrm{p}=0.065$ \\
Group 2 & $\mathrm{X}$ & Group 3 & $\mathrm{p}=0.609$ \\
Group 2 & $\mathrm{X}$ & Group 4 & $\mathrm{p}=1.000$ \\
Group 3 & $\mathrm{X}$ & Group 4 & $\mathrm{p}=0.636$ \\
\hline
\end{tabular}

Teste t-Student $(\mathrm{p}<0.05)$ 
All groups evolved to circulatory failure homogeneously.

While statistical analysis has shown that variables (heart rate and central venous pressure) were significant different between groups with respective $p=0.023$ and $p=0.04$, this fact did not change the course for circulatory failure.

The mean arterial pressure and oxygen saturation were not statistically significant (Figures 1 to 4 ).

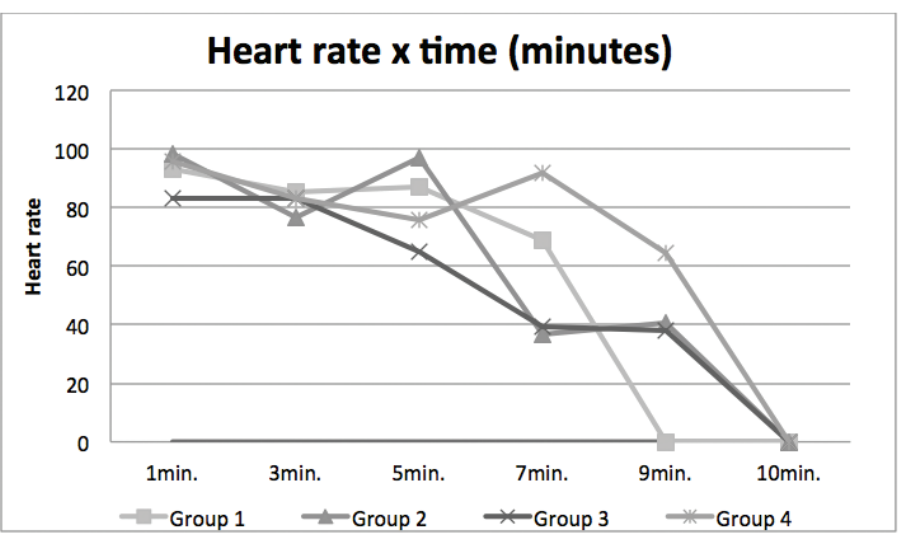

FIGURE 1 - The heart rate versus time in minutes $(\mathrm{p}=0.023)$.

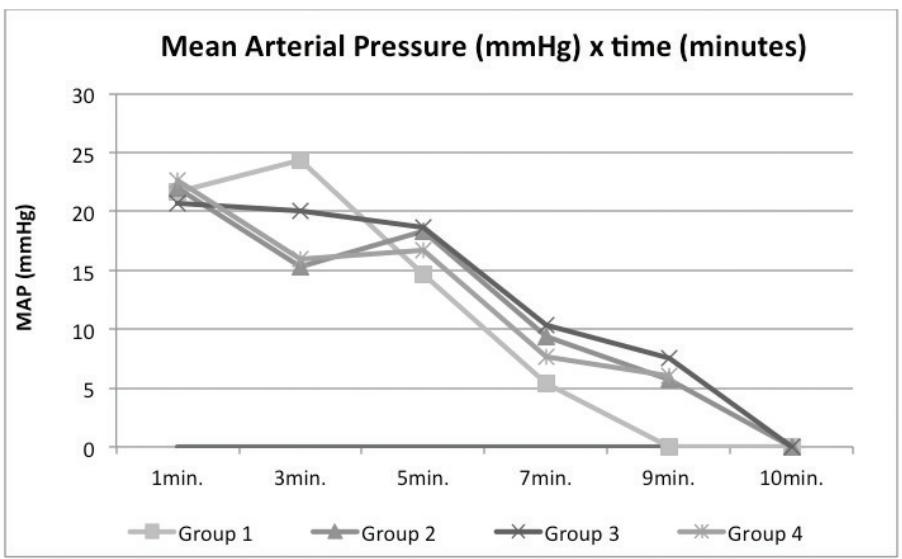

FIGURE 2 - The mean arterial pressure to time in minutes $(\mathrm{p}=0.815)$.

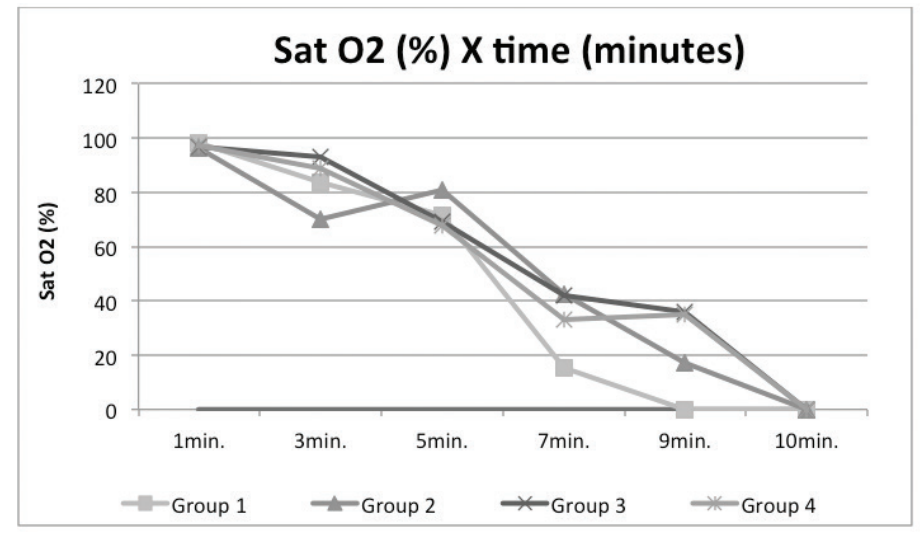

FIGURE 3 - The $\mathrm{O}_{2}$ saturation to time in minutes $(\mathrm{p}=0.948)$.

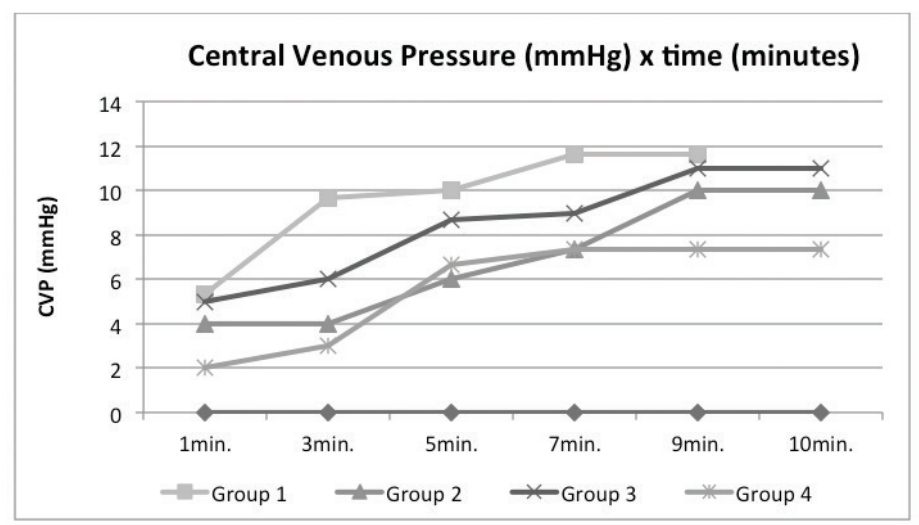

FIGURE 4 - The central venous pressure to time in minutes $(p=0.040)$.

\section{Discussion}

Despite the favorable results of the use of preconditioning to facilitate engraftment in small animals ${ }^{1}$, there is still no standardization of DCD experimental model and the hemodynamic effects that ischemic remote preconditioning can cause for the donors.

Interestingly, studies in swine have physiological aspects similar to humans, which can theoretically simulate the effects of remote preconditioning in a donor ${ }^{14}$.

This study supports the applicability of the proposed protocol by Morais et al. ${ }^{13}$ This method has no pharmacological drugs interference, which could compromise graft function by influencing the $\mathrm{Na} / \mathrm{K}$ transport between membranes, neither the precocious effects of ischemia-reperfusion injury provided by exsanguination described by Schön et al. ${ }^{15}$, nor the imprecise analysis of variables and outcomes in the model proposed by Sato et $a l .{ }^{16}$, once the latter is absent of specification of electrocardiographic criteria and points high variability of time between the withdrawal of life support and cardiac arrest ${ }^{15,16}$. Since no pharmacologic agents or life support withdraw were used in our study with the intent of cardiac arrest, we speculate that organ preservation can be achieved with minimal experimental bias.

Our results have shown that the surgical protocol proposed by Morais et al. ${ }^{13}$ is reproducible, easily performed and applicable to other experimental studies on remote ischemic preconditioning. A homogenous circulatory collapse can be obtained by the end of nine minutes with a small difference of time from the one reported by Morais et al. ${ }^{13}$ (seven minutes) and with a similar hemodynamic pattern. Although a little delay in the remote preconditioning time of death whose mechanisms do not matter to this study, it does not invalidate this model and corroborates the perspectives of Morais et $a l .{ }^{13}$ Only groups 3 and 4 did not show significant statistical difference, nevertheless, their tendencies followed group 2. 
Considering that there is a lack of standardization of DCD for transplants, this model can be considered a sui parameter for further studies regarding the preservation of organ transplants. Thus, it brings new perspectives of uniformity for further controlled studies of DCD. Once uniformized methods for DCD donation exist, events such as ischemic remote preconditioning and other methods of graft tolerance promotion might as well be better studied, in a more controlled and less biased way.

The finding of delay in death time may be very important for future studies that use this method to achieve a greater tolerance for the graft towards the effects of ischemia and reperfusion, because these grafts taken from donors may have greater effect of ischemia and reperfusion. Further studies of transplanting organs could tell us what impact this method may offer to the transplanted graft.

We also believe that the reproducibility of the method may be useful to the rational use of animals in studies of DCD organ donation. Economic savings might be another benefit to consider, as well as the usefulness of the method on simulating the Maastricht's category IV of DCD ${ }^{13}$.

\section{Conclusion}

The model is feasible and was easily reproduced. The remote ischemic preconditioning tends to a slight increase in circulatory failure time.

\section{References}

1. Torras J, Herrero-Fresneda I, Lloberas N, Riera M, Ma Cruzado J, Ma Grinyo J. Promising effects of ischemic preconditioning in renal transplantation. Kidney Int. 2002;61:2218-27.

2. Murry CE, Jennings RB, Reimer KA. Preconditioning with ischemia: a delay of lethal cell injury in ischemic myocardium. Circulation. 1986;74:1124-36.

3. Maathuis MH, Leuvenink HG, Ploeg RJ. Perspectives in organ preservation. Transplantation. 2007;83:1289-98.

4. Grenz A, Zhang H, Eckle T, Mittelbronn M, Wehrmann M, Köhle C, Kloor D, Thompson LF, Osswald H, Eltzschig HK Protective role of ecto-5'-nucleotidase (CD73) in renal ischemia. J Am Soc Nephrol. 2007;18(3) 833-45.

5. Rela M, Jassem W. Transplantation from non-heart-beating donors. Transplantation Proc. 2007;39:726-7.

6. Hosgood SA, Bagul A, Yang B, Nicholson ML. The relative effects of warm and cold ischemic injury in an experimental model of nonheartbeating donor kidneys. Transplantation. 2008;85:88-92.

7. Monton S, Herrera J, Ferrer JV, Guerrero D, Balen E, Lera JM. Experimental model of non-heart-beating donors: oxidative stress metabolism in kidney after cardiac arrest (30 minutes of warm ischemia) and reimplantation 24 hours later. Transplantation Proc. 1999;31:2350-1.

8. Joris J, Kaba A, Lauwick S, Lamy M, Brichant JF, Damas P, Ledoux D, Damas F, Lambermont B, Morimont P, Devos P, Delbouille MH, Monard J, Hans MF, DeRoover A, Honoré P, Squifflet JP, Meurisse
M, Detry O. End of life care in the operating room for non-heartbeating donors: organization at the University Hospital of Liege. Transplantation Proc. 2011;43:3441-4.

9. Koo DD, Welsh KI, Roake JA, Morris PJ, Fuggle SV. Ischemia/ reperfusion injury in human kidney transplantation: an immunohistochemical analysis of changes after reperfusion. Am J Pathol. 1998;153:557-66.

10. Abboud I, Viglietti D, Antoine C, Gauldez F, Meria P, Tariel E, Mongiat-Artus P, Desgranchamps F, Roussin F , Fieux F, Jacob L, Randoux C, Michel C, Flamant M, Lefaucheur C, Pillebout E, Serrato T, Peraldi MN, Glotz D. Preliminary results of transplantation with kidneys donated after cardiocirculatory determination of death: a French single-centre experience. Nephrol Dial Transplant. 2012;27:2583-7.

11. Frutos MA, Sola E, Mansilla JJ, Ruiz P, Martin-Gomez A, Seller G. Expanded criteria donors for kidney transplantation: quality control and results. Transplantation Proc. 2006;38:2371-3.

12. Remuzzi G, Cravedi P, Perna A, Dimitrov BD, Turturro M, Locatelli G, Rigotti P, Baldan N, Beatini M, Valente U, Scalamogna M, Ruggenenti P. Long-term outcome of renal transplantation from older donors. N Engl J Med. 2006;354:343-52.

13. Morais LK, Silva Júnior PM, Moreno JC, Brasil AM, Camarço JP, Martins SB, Quireze Júnior C. Non heart beating organ donor: new experimental model in pigs. Acta Cir Bras. 2012;27:306-10.

14. Giraud S, Favreau F, Chatauret N, Thuillier R, Maiga S, Hauet T. Contribution of large pig for renal ischemia-reperfusion and transplantation studies: the preclinical model. J Biomed Biotechnol. 2011;2011:532127.

15. Schön MR, Kollmar O, Wolf S, Schrem H, Matthes M, Akkoc N, Schnoy NC, Neuhaus P. Liver transplantation after organ preservation with normothermic extracorporeal perfusion. Ann Surg. 2001;233:114-23.

16. Sato M, Ohkohchi N, Tsukamoto S, Koyamada N, Asakura T, Enomoto Y, Usuda M, Miyagi S, Okada A, Satomi S. Successful liver transplantation from agonal non-heart-beating donors in pigs. Transpl Int. 2003;16:100-7.

\section{Correspondence:}

Claudemiro Quireze Júnior

Faculdade de Medicina, UFG

Divisão de Cirurgia Digestiva

Departamento de Cirurgia

Rua 7, 247/902 Setor Oeste

74110-090 Goiânia - GO Brasil

Tel.: (55 62)3269-8204

cquirezejr@gmail.com

Received: Oct 23, 2013

Review: Dec 20, 2013

Accepted: Jan 21, 2014

Conflict of interest: none

Financial source: none

${ }^{1}$ Research performed at Laboratory of Experimental Surgery and Anesthesiology, School of Veterinary and Animal Science, Federal University of Goias (EVZ/UFG), Goiania-GO, Brazil. Part of Master degree thesis, Postgraduate Program in Health Sciences. Tutor: Prof. Dr. Claudemiro Quireze Júnior. 